\title{
Effective Evaluation of Teachers' Non-verbal Behaviour in Classrooms
}

\author{
* Dr. Mahrukh Shakir, Assistant Professor (Corresponding Author)
}

\begin{abstract}
This study attempts to develop a comprehensive scale or instrument for measurement or evaluation of teachers' non-verbal behavior based on a review of a range of relevant literature. The theoretical proposition in literature argues that teacher's immediacy behavior directly influences students' motivation, which in turn influences students' learning. Given the literature report of the high influence of teachers' behavior on learners' motivation and ultimately learning, it was deemed important to develop such a scale which could evaluate how teacher's behavior affects students' motivation in a classroom setting, to the benefit of the relevant stakeholders. This could be better determined by students' motivation through their perceptions and interpretations of such behavior. To this end, a sample of 51 students, including 22 males and 28 females was drawn from a public sector university in Pakistan. Significance and conclusion of the study are drawn, and suggestions are put forth based on research made in this study.
\end{abstract}

Keywords: $\quad$ Non-verbal, Questionnaire, Behavior, Motivation, Demotivation Introduction

In light of the significance of teachers' role as motivators, and the effects (positive or negative) of these teachers' behaviors on students' motivation (Hsu, 2010; Velez \& Cano, 2008; Gorham \& Christophel, 1992), the students' belief on what generates motivation is important and requires to be considered (Vural, 2007). This justifies the importance of students' perceptions as students' perceptions concerning teachers' motivational behaviors might be more relevant than the perceptions of external observers and/or general beliefs pointed out in the literature (ibid). Further, students' perception of teachers' behaviors better determines learner's behaviors (attitude, perception, motivation, emotions, values, and beliefs) towards other learning factors in class (Subahan, 1990). Also, teachers' awareness about their students' perceptions of teachers' motivating and de-motivating behaviors might help teachers in evaluating the effects of their behaviors (ibid). With these things in mind, I intend to develop a comprehensive scale that could evaluate teachers' motivating and demotivating nonverbal (immediacy) behaviors through students' perceptions. But since, the relevant research and teaching practices on teaching effectiveness give more emphasis on improvement and analysis of verbal behaviors than non-verbal behaviors of teachers (Sprinthall \& Sprinthall, 1994), particularly, the impact of individual nonverbal (immediacy) behaviors on students' motivation, this study research will focus only on 'non-verbal (immediacy) behavior' of teachers.

\section{Literature Review}

\section{Nonverbal Behaviour}

Nonverbal behavior encompasses the "messages other than words that people exchange" (Gregersen, 2007: 52). Babad (2009) described nonverbal behavior very clearly and precisely as; "Nonverbal behavior' involves all such expressive aspects which do not have a verbal content (words or spoken or/and written language). According to Gregersen (2007), "it includes both overt behavior such as facial expressions, touching, eyes; and less obvious messages such as postures, dress, and spatial distance between people" (p. 3).

The effective communication between students and teachers in a class gets handicapped without the appropriate use of nonverbal behaviors (Negi, 2009). For classroom instructors, nonverbal behaviors are not merely an "add on" to their verbal utterances, but sometimes the unspoken messages can even outweigh what has been said and can also alter the dynamics of a conversation (McCafferty \& Stam, 2008). For example, a smiling face may serve to enhance approachability and friendliness, and using a simple touch on the shoulder designating a student for participation in a class activity might communicate a sense of care and encouragement (ibid).

* Department of English, Abdul Wali Khan University Mardan Email: mahrukh@awkum.edu.pk 
Nonverbal immediacy is described as the implicit employment of closeness inducing behavioral cues (Andersen, 1979). Nonverbal immediacy is a relational language that is perceived to communicate affective feelings of closeness, belonging, and warmth (Richmond, Gorham, \& McCroskey, 1987) and enhances impressions of trust, likeability, and approachability (Mehrabian, 1981). Nonverbal immediacy is connected to availability for approachability, communication, as well as to enhanced closeness, interpersonal warmth, and sensory stimulation (Andersen, 1985).

According to Richmond et al. (1987) and Rifkind \& Harper (1993), non-verbal immediacy behavior includes physical behaviors such as leaning forward, facial expressions, smiling, relaxed body position, physical proximity, appropriate touch, vocal varieties, using gestures, and maintaining eye contact while talking to students, nodding head, moving around the classroom during teaching, and dressing.

\section{Research Objectives}

Given the focus of this paper, the following are the research objectives:

1) To review the main research studies which focuses on teachers' non-verbal behavior

2) To develop a comprehensive scale for the evaluation and measurement of teachers' nonverbal behavior

\section{Research Questions}

Q1) How do the main relevant research studies focus on teachers' non-verbal behavior?

Q2) How to develop a comprehensive scale for the evaluation and measurement of teachers' nonverbal behavior based on these studies?

\section{Methodology}

Because of the above-mentioned aims of this paper, a questionnaire was designed which contained 38 closed-ended items and 2 open-ended questions at the end. The open-ended questions were included to allow for respondents' clear voice on their views on teachers' nonverbal (immediacy) behaviors. Dornyei (2009) also suggests using few open-ended questions by explaining that "in more applied studies when we are looking at concrete questions concerning real people, a primarily quantitative summary may lose some of the edge and flavor of the original issue. So, a few open-ended items in the questionnaire might play a useful role in providing quotations that can help to retain or restore the real perspective" (p. 66).

\section{Construction of the Questionnaire/Scale}

Items for questionnaires were derived from the previous research studies on teachers' nonverbal (immediacy) behavior. In an attempt to cover maximum nonverbal behaviors, and to have an exhaustive list of all possible nonverbal behaviors, I first listed all the nonverbal behaviors that I had in my mind, emerging from my experiences as a student and teacher i.e. those behaviors of the teachers whichever had in my learning and teaching experiences caused my motivation or demotivation. Next, I searched as many questionnaires used in previous studies as possible to have a detailed list. In these studies, the most commonly used (hereafter called as 'main') Nonverbal Immediacy Scale (NIS) for measuring learners' perceptions of instructor's nonverbal immediacy behaviors is the one developed by Richmond, Gorham \& McCroskey (1987) consisting of 14 items (see figure 2 below). They revised this scale to its present version to provide a scale that is consistent across class subjects and cultures. It has been employed in the majority of research on immediacy in teaching (e.g. Burroughs, 1990; Christophel, 1990; Fryrnier, 1994; Powell \& Harville, 1990; Sanders \& Wiseman, 1990; Thompson, 1992; Thomas, Richmond, \& McCroskey, 1994). Also, in some recent studies (e.g. Hsu, 2010; Pribyl, Sakamoto \& Keaten, 2004), the same NIS has been used. This scale showed summated reliabilities ranging from .73 to .89 (Richmond et al., 1987; Gorham, 1988; Christophel, 1990; Frymier, 1994). This instrument served as a starting point or a base for developing my 38 items questionnaire. Followed by looking at other studies, I combined some factors from other nonverbal immediacy scales (see figure $3 \& 4$ below) used in other studies which I felt could be necessary for my study but not addressed in the main questionnaire. Conversely, any aspect already mentioned in the main questionnaire but repeated in another, I would skip that. In the end, I matched the resultant questionnaire to my initial list based on my experiences and added all those items that were not present in the resultant questionnaire (see figure 1 below). In other words, items that had not been addressed in any of those already used scales in other researches.

Some of the factors (statements) from these already existed questionnaires were taken as they are, while some were changed and adapted slightly, considering those students who lack high English 
proficiency as the questionnaire is aimed for students to know their perceptions. For making the language easy for students' readability and better comprehension, I changed the words to simple and easy wordings and short sentences in cases where I picked up the already used items. According to Vijver and Leung (1997), while no researcher can claim to have a perfectly valid instrument, the use of methods to determine and limit bias, lessen the chances of bias significantly especially while measuring a phenomenon across cultures. "Changing questions into more easily understandable phrases that contain the substance, if not the exact words, is a valid translation method known as cultural de-centering" (Vijver \& Leung, 1997: 39). Also, I coded and sequenced the questions (putting those questions together which are closely associated) to make the progression from one to the next question smoother and fluent for the respondents. But since the sequence of these different items is not a crucial factor for filling up the questionnaires, therefore much attention and time has not been consumed on this aspect. In all, I tried my best to make the questionnaire as reliable and valid as possible to have authentic data to the maximum. Detailed stepwise formulation of the questionnaire and adaptation of the already used instruments is explained in the next section.

\section{Figure 1: Questionnaire}

The purpose of this survey is to assess the non-verbal teacher behavior in the classroom. The statements below show the aspects of nonverbal immediacy that a teacher may display in a classroom environment which some students find motivating and others find de-motivating. Motivation means that which arouses your interest, involvement, or positive attitude towards the subject being taught to you. De- motivation means which arouses your disliking or negative attitude or affect your involvement in the task. Please choose the aspects, the presence or absence of which you believe are motivating or de-motivating in any teacher from your real-life during two years of M.A experience. We seek your help in completing this survey.

Name:

Program:

Gender:

Year of study:

Age:

Email ID:

Please TICK or CIRCLE any option which best represents your feelings. There is no correct answer. Simply record your perceptions. Some of the questions may seem similar but kindly answer all. Use an extra page if necessary.

\begin{tabular}{|c|c|c|c|c|}
\hline S. No & \multicolumn{2}{|c|}{ Statements } & Scale Used & \\
\hline \multicolumn{5}{|c|}{$\begin{array}{l}\text { Physical Proximity/Touch } \\
\end{array}$} \\
\hline 1. & $\begin{array}{l}\text { The teacher touches on the hand/forearm/shoulder } \\
\text { when talking to students (you or any other). }\end{array}$ & Motivating & De-motivating & No Effect \\
\hline 2. & $\begin{array}{l}\text { The teacher pats the shoulder of students when } \\
\text { talking to them (you or any other). }\end{array}$ & Motivating & De-motivating & No Effect \\
\hline 3. & $\begin{array}{l}\text { The teacher avoids touching students when talking } \\
\text { to them (you or any other). }\end{array}$ & Motivating & De-motivating & No Effect \\
\hline 4. & $\begin{array}{l}\text { The teacher sits close to students when talking to } \\
\text { them (you/any other/all). }\end{array}$ & Motivating & De-motivating & No Effect \\
\hline 5. & $\begin{array}{l}\text { The teacher stands close to students when talking } \\
\text { to them (you/any other/all). }\end{array}$ & Motivating & De-motivating & No Effect \\
\hline 6. & $\begin{array}{l}\text { The teacher moves closer when talking to students } \\
\text { (you/some/all). }\end{array}$ & Motivating & De-motivating & No Effect \\
\hline \multicolumn{5}{|c|}{ Body Movement/Orientation } \\
\hline 7. & $\begin{array}{l}\text { The teacher leans forward/backward/sideways } \\
\text { when talking to the students (You or any other). }\end{array}$ & Motivating & De-motivating & No Effect \\
\hline 8. & The teacher sits behind the desk while teaching. & Motivating & De-motivating & No Effect \\
\hline 9. & $\begin{array}{l}\text { The teacher stands behind the desk/podium while } \\
\text { teaching. }\end{array}$ & Motivating & De-motivating & No Effect \\
\hline 10. & $\begin{array}{l}\text { The teacher stands in front of the class when } \\
\text { teaching. }\end{array}$ & Motivating & De-motivating & No Effect \\
\hline 11. & $\begin{array}{l}\text { The teacher moves around the classroom while } \\
\text { teaching. }\end{array}$ & Motivating & De-motivating & No Effect \\
\hline \multicolumn{5}{|c|}{ Gestures } \\
\hline 12. & $\begin{array}{l}\text { The teacher nods head when talking to students } \\
\text { (you/any other/all). }\end{array}$ & Motivating & De-motivating & No Effect \\
\hline 13. & The teacher shakes head when talking to students & Motivating & De-motivating & No Effect \\
\hline
\end{tabular}


(you/any other/all).

14. The teacher gestures while talking to the class.

15. The teacher avoids gestures while talking to Motivating

De-motivating

No Effect students (you/any other/all).

16. The teacher is serious when talking to students Motivating (you/any other/all).

17. The teacher listens patiently to students when Motivating talking to students (you/any other/all).

18. The teacher is always in a rush/hurry while in Motivating class.

19. The teacher uses hands/arms to gesture while Motivating talking to/teaching students.

20. The teacher keeps his/her hands in his/her pocket. Motivating

\section{Body Position}

21. The teacher has a very relaxed body position while Motivating talking to the class.

22. The teacher has a very tense body position while Motivating talking to the class.

23. The teacher moves or acts nervously or restlessly Motivating in class.

\section{Appearance/dress}

24. The teacher has an informal appearance/dress. Motivating Facial Expressions

25. The teacher smiles at individual students in the Motivating class.

26. The teacher smiles when students interact and ask Motivating questions.

27. The teacher is silent on students' misbehaviors. Motivating

28. The teacher is cheerful when talking to students Motivating (you/any other/all).

29. The teacher has a cold facial expression when Motivating talking to students (you/any other/all).

30. The teacher seems tough/stern when talking to Motivating students (you/any other/all).

31. The teacher has a tense face when talking to Motivating students (you/any other/all).

32. The teacher has a relaxed face when talking to Motivating students (you/any other/all).

33. The teacher frowns at the class while talking. Motivating

34. The teacher's face is animated when talking to Motivating students (you/any other/all).

\section{Eye Contact/Movement}

35. The teacher looks at the board or notes while Motivating talking to the class.

36. The teacher maintains eye contact with the class Motivating when talking to it.

37. The teacher maintains eye contact with individual Motivating students when talking to them.

38. The teacher avoids eye contact while talking to Motivating students (you/any other/all).

De-motivating

No Effect

De-motivating No Effect

De-motivating No Effect

De-motivating No Effect

De-motivating No Effect

De-motivating No Effect

De-motivating No Effect

De-motivating No Effect

De-motivating No Effect

De-motivating No Effect

De-motivating No Effect

De-motivating No Effect

De-motivating No Effect

De-motivating No Effect

De-motivating No Effect

De-motivating No Effect

De-motivating No Effect

De-motivating No Effect

De-motivating No Effect

De-motivating No Effect

De-motivating No Effect

De-motivating No Effect

De-motivating No Effect

De-motivating No Effect

1) How the above-mentioned teachers' nonverbal behaviors increased your motivation in the class?

2) How the above-mentioned teachers' nonverbal behaviors decreased your motivation in the class?

I have tried to make this questionnaire as comprehensive as possible but if you feel that there are things that I have missed out on, please write below what you think? 
I accept/do not accept the invitation to be contacted in case of a follow-up interview (tick one) Thank you once again for completing this questionnaire. Your valuable responses will be used to help me to evaluate teachers' behavior effectively.

Adaptation of previously used NVI scale

The commonly used NIS questionnaire (see figure 2 below) has been adapted to its present version as follows; Items relating to standing, touching, or sitting were later on observed to be poor items when evaluating lecturers by McCroskey, et al., (1996), so they modified the initial 14-Item Nonverbal Immediacy Measure by removing \#1, \#7, \#9, and \#11. But I found them quite relevant nonverbal behaviors, in my opinion, so I have not excluded them from my questionnaire. Thus the factors 8,9 , $11,14,21,22,25,----, 35$ in my questionnaire corresponds to factors $1,11,8,2,12,6,13,---, 10$ respectively in the commonly used NIS. Concerning factor 33 in my questionnaire, I added this one as had been suggested by McCroskey et al., (1996) for substitution for factor 13 in NIS in future studies on nonverbal immediacy. But considering factor 13 as equally important nonverbal behavior, I added my factor 33 in addition to NIS item \#13 instead of substituting it for \#13 in the adapted questionnaire. Concerning, factors 3 and 14 in the NIS, though they had been regarded as nonverbal by many researchers (e.g. Andersen, 1979; Richmond et al., 1987; Rifkind \& Harper, 1993), and included in studies (e.g. Hsu, 2010; McCroskey et al., 1996) using this scale for measuring nonverbal immediacy behavior but despite reflecting deeply over these two factors, never did I get convinced to include them as nonverbal behaviors. To my judgment, they contain some verbal elements though they are not exclusively either verbal or nonverbal. But these two factors, containing a very thin line difference, in my opinion, are quite controversial for me. Hence, I excluded them from my questionnaire.

Figure 2: Nonverbal immediacy behavior scale (NIS)

Directions: Below are a series of descriptions of things some teachers have been observed doing in some classes. Please respond to the statements in terms how well they apply to this teacher. Please use the following scale to respond to each of the statements:

Score your teacher using the 5-point scale as:

Never $=0$, Rarely $=1$, Occasionally $=2$, Often $=3$, and Very Often $=4$.

1. Sits behind desk while teaching. 01234

2. Gestures while talking to class. 01234

3. Uses monotone/dull voice when talking to class. 01234

4. Looks at class while talking. 01234

5. Smiles at the class as a whole, not just individual students. 01234

6. Has a very tense body position while talking to the class. 01234

7. Touches students in the class. 01234

8. Moves around the classroom while teaching. 01234

9. Sits on a desk or in a chair while teaching. 01234

10. Looks at the board or notes while talking to the class. 01234

11. Stands behind podium or desk while teaching. 01234

12. Has a very relaxed body position while talking to the class. 01234

13. Smile at individual students in the class. 01234

14. Uses a variety of vocal expressions while taking to the class. 01234

Some factors have been taken from a study by Ozmen (2011). Though different in terms of research participants where perceptions of teachers about effective teachers in terms of nonverbal immediacy behaviors are the main source of data, this study contains quite a long list of teacher's nonverbal behaviors as compared to other studies I have come across so far. This study thus had the possibility of covering almost all aspects of the teacher's nonverbal immediacy behaviors. Hence, factors $1,3,4,5,6,15,19,28,29,30,36,37$, and 38 in my questionnaire corresponds to factors 2, 26, $10,16,20,1,25,14,15,18,22,28$, and 8 in the Ozmen's (2011) Nonverbal Immediacy Scale- Self report (NIS-S) (figure 3). While factors 2, 12, 34, and 36 in my questionnaire correspond to factors 6 , 12,10 , and 7 in the Nonverbal Immediacy behavior (NVI) list (figure 4) from the same study by Ozmen (2011). These factors were not present in the most commonly used NIS (figure 3). 
Figure 3: Nonverbal Immediacy Scale-Self Report (NIS-S)

Respond to the following statements in terms of the qualities of an effective English teacher

-1 . I use my hands and arms to gesture while talking to my students.

2. I touch my students on the shoulder or arm while talking to them.

3. I use a monotone or dull voice while talking to my students.

4. I look over or away from my students while talking to them.

5. I move away from my students when they touch me while we are talking.

6. I have a relaxed body position when I talk to my students.

7. I look tense while talking to my students.

8. I avoid eye contact while talking to my students.

9. I have a tense body position while talking to my students.

10. I sit close or stand close to my students while talking with them.

11. My voice is monotonous or dull when I talk to my students.

12. I use a variety of vocal expressions when I talk to my students.

13. I gesture when I talk to my students.

14. I am cheerful when I talk to my students.

15. I have a cold facial expression when I talk to my students.

16. I move closer to my students when I talk to them.

17. I look directly at my students while talking to them.

18. I am tough when I talk to my students.

19. I have a lot of vocal variety when I talk to my students.

20. I avoid gesturing while I am talking to my students.

21. I walk toward my students when I talk to them.

22. I maintain eye contact with my students when I talk to them.

23. I try not to sit or stand close to my students when I talk with them.

24. I walk away from my students when I talk to them.

25 . I smile when I talk to my students.

26. I avoid touching my students when I talk to them.

The remaining 7, 10, 13, 20, 23, 24, 31, 32 factors were taken from a chapter by Babad (2007), and the rest $16,17,18,26$, and 27 in my questionnaire belong to my initial list, not addressed in any of the above-mentioned questionnaires and based on my own experiences as a student and teacher. Additionally, the questionnaire consisted of an element not part of the common immediacy research i.e. two open-ended questions at the end.

\section{Figure 4: Nonverbal immediacy behaviors}

\section{Behaviors}

1-Physicalproximity

$2-$

$3-$

4-Bodyorientation

5-Touch

6-

7-Eye Contact

$8-$

9-

10-Smiling

A teacher displaying nonverbal immediacy
Moves closer when talking to another
Stands closer to a person when talking to them
Sits closer to a person when talking to them
Leans forward when talking with another
Touch on the hand, forearm, shoulder when talking to
another
Patting the shoulder of another when talking to them
Eye contact with the group as a whole when talking to
them
Eye contact with individuals when talking to them
Looking in the general direction of another when talking
To them
Face is animated when talking to another


$11-$

12-Body Movement

$13-\&$ Gestures

$14-$

15-Bodyposture

16-Vocal

17-Expressiveness

$18-$

Smiles when talking to another
Nods head when talking with another
Use hands and arms to gesture when talking to another
Calmly moves body around when talking with another
Body posture is relaxed when talking with another
Changes in pitch and tempo of voice when talking to
another
Short pauses when talking to another
Relaxed tones when talking to another

Content of the Resultant Questionnaire

The first section of the questionnaire (see figure 1) contained detailed instructions for the participants. The subsequent section asked for demographic information i.e. blank spaces were left for soliciting, from the participants, their gender, age, program and year of study, their name and email ID (for contacting them in case of follow-up interview). This was followed by a list of 38 nonverbal immediacy questions. These 38 teachers' nonverbal behavior descriptors were grouped into seven broader categories or variables. Dornyei (2009) suggests that a "well-designed questionnaire contains several items focused on each content area and therefore the parallel items need to be summed up in multi-item scales for analysis. By doing so we can create fewer but broader variables that carry almost as much information as the original variables" (p. 92). Out of the total 38 listed variables, $16 \%$ was related to physical proximity, $13 \%$ to body movement/orientation, $24 \%$ to gestures, $8 \%$ to body position, 3\% to informal appearance/dress, $26 \%$ to facial expressions, and $11 \%$ to eye contact/movement. Each question or variable was assessed on a multi-item scale having options (motivating, de-motivating, no effect). The seven broader variables are as follows:

\section{Physical Proximity/Touch}

The variable 'Physical proximity/touch' here refers to those teacher's non-verbal behavior that exhibits teachers' physical nearness to students in terms of whole or any part of their body. As shown in the questionnaire, it further consists of 6 items or sub-variables (1- 6) of teacher's nonverbal behaviors, including teacher's 1) touching, 2) patting, 3) avoid touching students, and 4) sitting/ 5) standing 6) moving close to students.

\section{Body Movement/Orientation}

5 sub-variables (7- 11) referenced 'body movement/orientation'. Body movement implies whether the teacher moves or is fixed at someplace in the class i.e. if the teacher is not moving then what is his/her location in the class, while orientation here suggests physical inclination of teacher towards students. These 5 sub-variables included 1) teacher leans forward/backward/sideways when talking to students, 2) teacher sitting/3) standing behind the desk during teaching, 4) standing in front of the class during teaching and 5) moving around in the class.

\section{Gestures}

The next variable 'gestures' included 9 (12- 20) sub-variables. 'Gestures' here means using body parts or motion of the body parts as a means of expression. This variable involved behaviors i.e. teacher 1) nods/2) shakes head, 3) gestures/4) avoids gestures, 5) looks serious 6) listens patiently/7) is in a rush, 8) uses hands and arm to gesture/9) hands and arm in a pocket.

\section{Body Position}

The next variable is 'body position' which refers to the impression the body as a whole creates such as the teacher has a 1) relax/2) tense body position, and 3) the teacher moves or acts nervously. These are three sub-variables (21-23) for the variable 'body position' in the questionnaire.

\section{Appearance/Dress}

The subsequent variable 'appearance/dress' refers to the appearance and/or dress of a teacher. This variable has only one item (24) as this item could not fit conceptually well under other variables. Hence, being one item, it is mentioned separately from other items in the questionnaire under the separate category. 


\section{Facial Expressions}

This variable relates to different impressions the face creates on account of its different expressions and is sub-categorized into 10 items (25-34) i.e. the teacher 1) smiles at the class 2) smiles on students interaction, 3) frowns, 4) is cheerful, 5)silent, has a 6) relax/ 7) tense face, and 8) cold /9) tough/10) animated facial expressions.

\section{Eye Contact/Movement}

The last variable refers solely to expressions sent through eye contact /movement and included 4 items (35-38). These are 1) teacher maintaining eye contact with the class/2) individual students, 3) looking at board/ notes and teacher 4) avoiding eye contact.

\section{Piloting}

Before collecting data, piloting was undertaken to test and judge the effectiveness of the abovementioned instrument. The pilot study aided in; developing and testing the adequacy and appropriacy of the research instrument, assessing whether the research instrument has useable results, whether the study technique was effective, whether the questionnaire was appropriate to the context, and detecting and resolving any difficulties that could arise during its use.

\section{Pilot Participants}

First, the instrument was piloted with a set of ten volunteer students (6 males and 5 females) postgraduate students from an English department of a Pakistani public sector university situated in the rural city of Mardan. Participants were chosen via a convenient sampling method where "a certain group of people [were] chosen for the study because they [were] available" (Fraenkel \& Wallen, 1993: 103). Easy access to the respondents was the main sampling criteria which better suited the research. Since the researcher is a serving lecturer in the sample university so collecting data from the same university was convenient and time-saving. These students completed the questionnaires.

\section{Pilot Instrument}

The initial questionnaire used 43 questions and an additional question asking students' perceptions/opinions and attitudes towards the scale. Reliability for the instrument was tested to adjust the scale accordingly. The scale initially had an alpha reliability of 0.65 .

Participants were asked to submit, in addition to their answers, their interpretation of every item's meaning to advance the clarity of the questions. They were requested to comment on the meaning, connotation, and phrasing of questions. Pilot-participants were invited to ask questions in case any item was unclear and were also asked for their feedback about the procedures being used.

\section{Post Pilot Interviews}

The pilot questionnaires were followed by short interviews with the pilot-participants. This enabled me to develop accuracy and consistency in instrument. Most participants showed their contentment with the questionnaire and questions, though adding a few suggestions and some insights regarding its design and items. This prompted a little modification of the questionnaire, such as removing redundant, irrelevant items from the questionnaire and some minor language-related adjustments (for making language simple and comprehensible). This helped in creating more exhaustive, unambiguous, and discrete items, hence improving the instrument validity (Cohen, Manion, \& Morrison, 2000).

The questionnaire was subsequently revised to its current shape in light of feedback obtained from the pilot study. Based on the pilot testing of the questionnaire, 38 items of the questionnaire were finalized and 5 eliminated from the initial instrument as they contributed negatively to the scale internal consistency (their item-test correlation was below 0.57). Next, the summated Cronbach alpha reliability for the revised instrument was calculated which turned out to be 0.71 .

\section{Reliability Statistics}

\begin{tabular}{cc}
\hline Cronbach Alpha & No of Items \\
\hline 0.71 & 38 \\
\hline
\end{tabular}

Also, option "not experienced at all" initially used as the $4^{\text {th }}$ option in the instrument ${ }^{1}$, was removed from the questionnaire based on the pilot feedback. This option was not marked by respondents in the $8 / 10$ pilot questionnaires. Also, it was contributing negatively to the statistical interpretation.

\footnotetext{
${ }^{1}$ Initial four options were: Motivating, De-motivating, no effect, Not experienced at all
} 
Based on the piloting experience, here are the meanings of some of the terms used in the questionnaire. As extra care, to avoid confusion and for uniform interpretation with that of the researcher's, the meanings of different terms related to "nonverbal behaviors" used in the questionnaire are given below which can be explained to the participants in the following manner:

- $\quad$ Listening patiently to students; means without any interruption or cutting them short while student(s) is talking to the teacher.

Relax; Relax implies 'at ease'

Gesture: teachers' sending nonverbal expressions relating to their verbal utterances as opposed to empty/ blank expressions.

Cheerful; behavior implying teacher's facial expression reflecting happiness and liveliness.

- $\quad$ Nod head; behavior of a teacher as a means of signifying involvement, affirmation, approval, or assent in a non-verbal communication.

Moving around in class: As opposed to the conventional way of the teacher standing in front of the class, the teacher moving around in the class during teaching.

Closer; teacher standing close to students during communication instead of them being at a distance.

Smiling: Smiling carries a positive connotation here implying an encouraging smile.

- $\quad$ Animated face; face conveying liveliness

- $\quad$ Patting the shoulder of a student i.e. taping gently with the hand as a sign of expressing soothe, caress, approval, encouragement, or affection while talking to them.

- $\quad$ Looks at the notes or board; when delivering a lecture to the class, the teacher looking at lecture notes or writing board rather than looking directly at the students.

Cold facial expressions; Expressions lacking warmth or human emotions.

Hands in pocket; means teachers' not using their hands or teachers without any hand's movement or gestures during lecture or communication with students

Informal dress/appearance; here implies appearance or dress that is characteristic of or suitable to casual or ordinary use as opposed to professional appearance.

- Stern/ tough impression, i.e. conveying rigidness marked by absence of softness.

\section{Conclusion}

Based on the available literature on the given focus, this study represented a small effort in adding thread to the huge tapestry of teachers' related research in a classroom setting in the pursuit of students' success. This has been achieved through its attempt of developing a piloted and empirically tested scale which could evaluate teachers' non-verbal behavior via determining students' motivation through their perceptions of such behavior. Other researchers can use this ready-made scale/questionnaire in similar studies which may save some of their energy and efforts.

\section{Recommendations/Implications}

This study may be significant in the following ways:

The empirically grounded argument that the teacher's nonverbal (immediacy) behavior impacts student's motivation may provide instructors and other education practitioners an empirically based understanding of the role of teacher's nonverbal behaviors.

\section{In Teacher Development Programs}

This study may generate useful knowledge in the pedagogically significant aspect of teachers' nonverbal behavior, which might serve as an important and valuable input for teacher education programs. Hence, the study can provide a foundation for designing future training courses on teacher's nonverbal behaviors in different contexts.

Once identified, particular nonverbal (immediacy) variables may be taught directly to new pre-service as well as in-service teachers for improving the learner-teacher relationship and students' motivation (Gorham, 1988).

Teachers can be provided training to express/adapt/modify or/and increase (immediacy) specific non-verbal behaviors to enhance motivation, which in turn, may "elicit more learning" (Allen, Witt \& Wheeless, 2006).

Discovering students' perceptions about teachers' non-verbal behaviors might be more fruitful as it might inform and enable educationists to arrange and adapt, in light of these 
perceptions teacher training courses on effective teachers' behaviors and to design instructions accordingly.

\section{Regarding Teachers in Class}

- $\quad$ This study may raise an awareness in teachers, working either in the same or different contexts to assess, reflect, and monitor their behavior, in terms of having a positive or negative influence on learners' motivation, and make required changes accordingly. In this way, teachers can avail such knowledge in their classrooms to make their teaching more effective.

- The teachers' understanding of those factors that learners perceive as de-motivating and motivating may ultimately enable them to better build up a classroom environment that enhances motivation.

- Currently practicing instructors' knowledge can be build up and their attitudes revised through this scale, perhaps for instance via the arrangement of different workshops on teachers' behavior.

Hence, this study might be of some use for teacher educators and teachers and other stakeholders to improve educational programs.

\section{References}

Allen, M., Witt, P. L., \& Wheeless, L. R. (2006). The Role of Teacher Immediacy as a Motivational Factor in Student Learning: Using Meta-Analysis to Test a Causal Model, Communication Education, 55(1), 21-31.

Andersen, J. F. (1979). Teacher immediacy as a predictor of teacher effectiveness. In D. Nimmo (Ed.), Communication yearbook 3 (pp. 543-559). New Brunswick, NJ: Transaction Books.

Andersen, P. A. (1985). Nonverbal immediacy in interpersonal communication. In A. W. Siegman \& S. Feldstein (Eds.), Multichannel integrations of nonverbal behavior (pp. 1-36). Hillsdale, NJ: Erlbaum.

Babad, E. (2007). Teachers' nonverbal behavior and its effects on students. In J. C. Smart - (Ed.), Higher Education: Handbook of Theory and Research (Vol. 22, pp. 219-280). Netherland: Springer.

Babad, E. (2009). Teaching and nonverbal behavior in the classroom. In L. Saha \& A. Dworkin (Eds.). International handbook of research on teachers and teaching. (pp. 797-807). Holland: Springer Science + Business Media LLC.

Burroughs, N. F. (1990). The relationship of teacher immediacy and student compliance-resistance with learning. Unpublished doctoral dissertation, West Virginia University, Morgantown.

Christophel, D. (1990). The relationship among teacher immediacy behaviors, student motivation, and learning. Communication Education, 39(4), 323-240.

Dörnyei, Z. (2009). Questionnaires in second language research: Construction, administration, and processing $\left(2^{\text {nd }}\right.$ ed.). New York: Routledge.

Fraenkel, J. R., Wallen, N. E., \& Hyun, H. H. (1993). How to design and evaluate research in education. Maidenhead: McGraw-Hill HE.

Frymier, A. B. (1994). A model of immediacy in the classroom. Communication Quarterly, 42, 133144.

Gorham, J. (1988). The relationship between verbal teacher immediacy behaviors and student learning. Communication Education, 37, 40-53.

Gorham \& Christophel (1992). Students' perceptions of teacher behaviors as motivating and demotivating factors in college classes. Communication Quarterly, 40(3), 239-252.

Gregersen, T. S. (2007). Language learning beyond words: Incorporating body language into classroom activities. Journal of Reflections on English Language Teaching, 6, 51-64.

Hsu, L. (2010). The impact of perceived teachers' nonverbal immediacy on students' motivation for learning English. Asian EFL Journal, 12(4), 188-204.

Mehrabian, A. (1971). Silent messages. Belmont, CA: Wadsworth.

Mehrabian, A. (1981). Silent messages: Implicit communication of emotions and attitudes (2nd ed.). Belmont, CA: Wadsworth.

McCafferty, S. G., \& Stam, G. (Eds.). (2008). Gesture: Second language acquisition and classroom research. New York: Routledge. 
McCroskey, J. C., Sallinen, A., Fayer, J. M., Richmond, V.P., \& Barraclough, R. A. (1996). Nonverbal immediacy and cognitive learning: A cross-cultural investigation. Communication Education, 4, 200-211.

Negi, J. S. (2009). The role of teachers' non-verbal Communication in the ELT Classroom. Journal of NELTA, 14(1), 101-109.

Özmen, K. S. (2011). Perception of Nonverbal Immediacy and Effective Teaching among Student Teachers: A Study across Cultural Extremes. International Online Journal of Educational Sciences, 3(3), 865-881.

Powell, R. G., \& Harville, B. (1990). The effects of teacher immediacy and clarity on instructional outcomes: An intercultural assessment. Communication Education, 39, 369-379.

Pribyl, C. B., Sakamoto, M., \& Keaten, J. A. (2004). Teacher nonverbal immediacy: The relationship between nonverbal immediacy, student motivation, and perceived cognitive learning among Japanese college students. Japanese Psychological Research, 46(2), 73-85.

Richmond, V. P., Gorham, J., \& McCroskey, J. C. (1987). The relationship between selected immediacy behaviors and cognitive learning. In M. McLaughlin (Ed.), Communication Yearbook (Vol 10, pp. 574-590). Beverly Hills, CA: Sage.

Rifkind, L. J., \& Harper, L. F. (1993). Competent verbal and nonverbal cross-gender immediacy behaviors. CUPA Journal, 47-54.

Sanders, J. A., \& Wiseman, R. L. (1990). The effects of verbal and nonverbal teacher immediacy on perceived cognitive, affective, and behavioral learning in the multicultural classroom. Communication Education, 39, 341-353.

Sprinthal and Sprinthal, (1994). Educational psychology: A developmental approach. Interamericana de España: McGraw-Hill.

Subahan, T. M. (1990). Pembinaan Alat kajian Untuk Mengukur Tingkah Laku Pengajaran di Sekolah dan di Universiti. Jurnal Pendidikan, 15: 43-64.

Thomas, C. E., Richmond, V. P., and McCroskey, J. C. (1994). The association between immediacy and socio-communicative style. Communication Research Reports, 11, 107-114.

Thompson, C. C. (1992). The relationships among teachers' immediacy behaviors, credibility, and social style and students' motivation and learning: Comparisons among cultures. Unpublished doctoral dissertation, West Virginia University, Morgantown.

Velez, J. J., \& Cano, J. (2008). The relationship between teacher immediacy and student motivation. Journal of agricultural education, 49(3), 76-86.

Vijver, F. J. R., \& Leung, K. (1997). Methods and data analysis for cross-cultural research. Thousand Oaks, CA: Sage.

Vural, K., F. (2007). Cognitive absorption and acceptance of student teachers related to the web. Unpublished doctoral dissertation, University Institute of Graduate Studies in Science, Ankara. 